\title{
Influence of Heart Rate on the Phases of the Left Heart Gycle in Exercise
}

\author{
Shigeo Nakakura, M.D., Stanley WEgner, and \\ Clarence M. Agress, M.D.
}

\begin{abstract}
The phases of the left heart cycle have been studied in young athletes at rest and after exercise utilizing vibrocardiographic and electrocardiographic data. The periods under study included electromechanical lag, isometric contraction, ejection, isometric relaxation, rapid filling, and diastasis. When compared to the length of the heart cycle ( $R-R$ interval) these periods were found to diminish linearly with decreased cycle length and the range of the periods was such that the duration of each phase could be predicted from cycle length. At cycle lengths shorter than 370 msec. (160 heart rate), the electromechanical lag, isometric contraction, isometric relaxation and rapid filling periods were found to plateau, the period of diastasis was completely eliminated and the period of ejection was found to shorten more markedly. It was suggested that a physiologic limit in heart rate is reached at this level.
\end{abstract}

I

NTEREST in the phases of the heart cycle was greatly stimulated by Wiggers ${ }^{1)}$ who studied the duration of cardiac events in animals and attempted to determine how they were altered in various physiological states. In the human subject, observations on the duration of cardiac phases have been limited by the lack of reliable techniques to determine these periods externally. Heart catheterization studies have contributed most of the information but normal subjects are rarely studied and severe exercise loads cannot be imposed.

Precordial vibrations have come into use in recent years for the study of cardiodynamic phases. Apex cardiograms ${ }^{2)-4)}$ and kinetocardiograms $s^{5)}$ have demonstrated the ability to measure the durations of the phases of left ventricular systole and diastole in the human. These same correlations have been established in the animal with vibrocardiography. ${ }^{67,7)}$ Although hemodynamic correlations with vibrocardiograms have not been made in the human subject, ${ }^{*}$ the close relationship of vibrocardiograms to apex or kinetocardiograms $^{8)}$ as well as the close similarity of vibration wave forms between the human and animal" permits the use of these correlations in the human subject.

From the Institute for Medical Research, Cedars of Lebanon Division, Cedars-Sinai Medical Center, 4751 Fountain Avenue, Los Angeles, California 90029.

* Since this article was written, vibrocardiograms have been recorded at human heart catheterization simultaneously with left ventricular pressure curves. The same hemodynamic correlations were found as reported for dogs. 
This study was undertaken to determine the effects of alterations in heart rate induced by exercise on the phases of the left heart cycle as determined from vibrocardiographic and electrocardiographic data.

\section{METHOD}

Fifteen subjects were chosen for this study. Their ages ranged from 17 to 41 and averaged 26.2 years. All of these subjects were actively engaged in strenuous competitive athletics. They were screened by physical examination, electrocardiogram, blood pressure, chest x-ray and history.

The transducer for recording vibrocardiograms was a Ling-Temco-Vought condenser microphone with a frequency response of 1.5 to $3,000 \mathrm{cps}, \pm 3 \mathrm{DB} .{ }^{8}$ ) The recording instrument was an Electronics-for-Medicine photographic recorder with a paper speed of $100 \mathrm{~mm}$. per sec. The microphone was attached to the subject's chest by means of an elastic strap at the fourth left parasternal area ${ }^{9)}$ and a dipolar chest lead affixed at the midaxillary lines near the fourth to fifth intercostal spaces for recording electrocardiograms.

The exercise test consisted of pedalling on a bicycle ergometer at a rate of $20 \mathrm{Km}$. per hour with no load for a period of $2 \mathrm{~min}$. The load was then increased step-wise at 2 kilopond (KP) levels until a maximum of $4 \mathrm{KP}$ was reached. The speed of the ergometer was held constant at $20 \mathrm{Km}$. per hour. The test was terminated when the subject's heart rate reached 200 or began to plateau.

Records were obtained of vibrocardiograms and electrocardiograms at rest and during 3 to 4 successive levels of exercise. Measurements of the phases of the left heart cycle were made directly from the oscillographic records of the vibrocardiograms and electrocardiograms. The periods of the left heart cycle which were measured are described below and illustrated in Fig. 1 and 2.

Period 1. Period 1 was measured from the onset of the QRS complex of EGG to the $\mathrm{H}$ point of the vibrocardiogram. This period represents the electromechanical lag period and is the period between excitation and pressure rise in the ventricle.

Period 2. Period 2 was measured from the $\mathrm{H}$ wave to the $\mathrm{J}_{2}$ wave of the

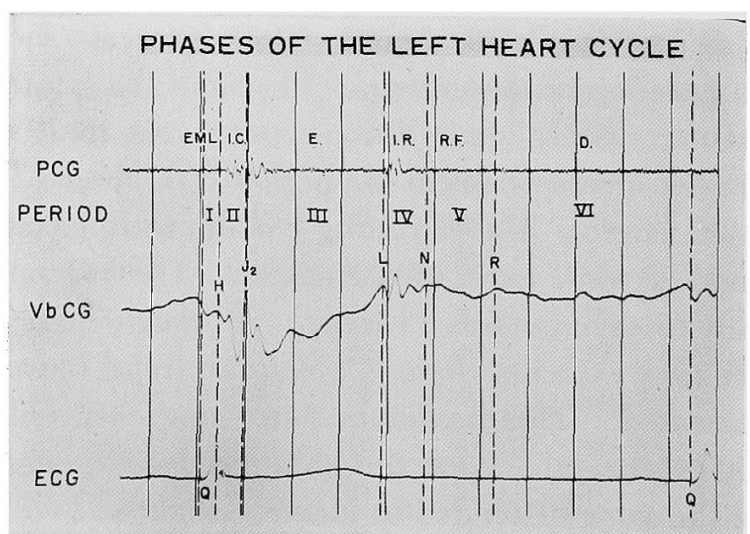

Fig. 1. Correspondence of the vibrocardiographic waves to the phases of the left heart cycle. 


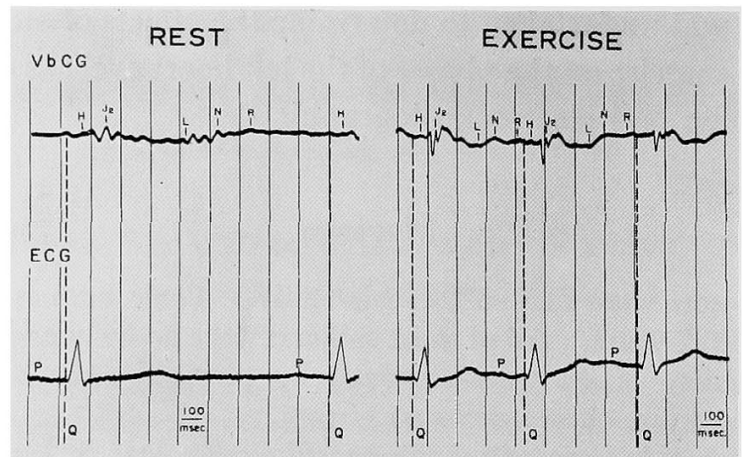

Fig. 2. Vibrocardiographic wave forms at rest and after cxcrcise.

vibrocardiogram. This period corresponds to the isometric contraction period.

Period 3. Period 3 was measured from the $\mathrm{J}_{2}$ wave to the $\mathrm{L}$ wave of the vibrocardiogram and represents the ejection period.

Period 4. Period 4 was measured from the $\mathrm{L}$ wave to the $\mathrm{N}$ wave of the vibrocardiogram and represents the period of isometric relaxation.

Period 5. Period 5 was measured from the $\mathrm{N}$ wave to the $\mathrm{R}$ wave of the vibrocardiogram and represents the rapid filling period.

Period 6. Period 6 was measured from the $\mathrm{R}$ point of the vibrocardiogram to the onset of the QRS complex of ECG and represents the period of diastasis or slow filling.

\section{Results}

Table I presents the durations of the 6 intervals measured at rest and during exercise in 15 subjects. The duration of the previous cardiac cycle is given as the cycle length.

The mean values for each of the 6 periods are presented in Table II with the corresponding previous cycle length ( $R-R$ interval) shown in the first column and the duration of the subsequent cycle in the "total " column. It can be seen that there is negligible difference between these 2 values.

In Fig. 3 the electromechanical lag period ( $\mathrm{QH}$ interval) is presented as a function of cycle length. Under resting conditions this period ranged from 39 to $50 \mathrm{msec}$. and 25 to $37 \mathrm{msec}$, after exercise. The average decrease of the interval from rest to exercise was $13 \mathrm{msec}$. Although there is a wide range both at rest and after exercise, there is a definite trend toward shortening as heart rate is increased. The maximum shortening occurred at cycle length of $370 \mathrm{msec}$. (160 heart rate). After this level the electromechanical lag period either remained the same or tended to increase slightly.

Fig. 4 shows the isometric contraction period $\left(\mathrm{H}-\mathrm{J}_{2}\right)$ as a function of cycle length. A linear change of this interval can be seen with cycle length. 
Table I. Duration of Each Period Before and After Exercise in msec.

\begin{tabular}{|c|c|c|c|c|c|c|c|c|c|c|}
\hline \multirow{2}{*}{$\begin{array}{l}\text { Case } \\
\text { No. }\end{array}$} & \multirow{2}{*}{ Name } & \multirow{2}{*}{ Age } & \multirow{2}{*}{ Condition } & \multicolumn{7}{|c|}{ Period } \\
\hline & & & & R-R & I & II & III & IV & V & VI \\
\hline \multirow[t]{4}{*}{3} & \multirow{4}{*}{ F. K. } & \multirow{4}{*}{21} & Control & 930 & 43 & 56 & 287 & 74 & 120 & 410 \\
\hline & & & Ex. 1 & 560 & 35 & 52 & 190 & 62 & 70 & 150 \\
\hline & & & 2 & 400 & 37 & 46 & 155 & - & - & - \\
\hline & & & 3 & 390 & 36 & 45 & 132 & 67 & 53 & 40 \\
\hline \multirow[t]{3}{*}{7} & \multirow[t]{3}{*}{ B. P. } & \multirow[t]{3}{*}{41} & Control & 1200 & 39 & 69 & 308 & 82 & 133 & 466 \\
\hline & & & Ex. 1 & 470 & 33 & 48 & 149 & 72 & 67 & 82 \\
\hline & & & 2 & 360 & 30 & 46 & 128 & 58 & 62 & 41 \\
\hline \multirow[t]{3}{*}{8} & \multirow[t]{3}{*}{ T. M. } & \multirow[t]{3}{*}{17} & Control & 1300 & 44 & 65 & 280 & 90 & 130 & 480 \\
\hline & & & Ex. 1 & 380 & 35 & 50 & 160 & 65 & 55 & 20 \\
\hline & & & 2 & 340 & 37 & 52 & 145 & 60 & 55 & 0 \\
\hline \multirow[t]{3}{*}{9} & \multirow[t]{3}{*}{ T. R. } & \multirow[t]{3}{*}{27} & Control & 1010 & 45 & 60 & 285 & 72 & 125 & 405 \\
\hline & & & Ex. 1 & 380 & 38 & 47 & 145 & 65 & 50 & 70 \\
\hline & & & 2 & 310 & 32 & 48 & 105 & 60 & 70 & 22 \\
\hline \multirow[t]{5}{*}{13} & \multirow[t]{5}{*}{ K. K. } & \multirow[t]{5}{*}{17} & Control & 980 & 43 & 60 & 275 & 75 & 120 & 430 \\
\hline & & & Ex. 1 & 440 & 30 & 53 & 160 & 65 & 60 & 80 \\
\hline & & & 2 & 380 & 28 & 50 & 138 & 60 & 70 & $30^{\circ}$ \\
\hline & & & 3 & 350 & 32 & 45 & 115 & 55 & 60 & 40 \\
\hline & & & 4 & 330 & 35 & 44 & 105 & 65 & 65 & 0 \\
\hline \multirow[t]{4}{*}{14} & \multirow[t]{4}{*}{ D. M. } & \multirow[t]{4}{*}{17} & Control & 910 & 40 & 60 & 255 & 80 & 115 & 360 \\
\hline & & & Ex. 1 & 580 & 35 & 50 & 200 & 65 & 70 & 160 \\
\hline & & & 2 & 500 & 35 & 50 & 180 & 65 & 70 & 115 \\
\hline & & & 3 & 320 & 28 & 50 & 130 & 55 & 50 & 25 \\
\hline \multirow[t]{4}{*}{15} & B. H. & 32 & Control & 850 & 40 & 60 & 268 & 70 & 95 & 300 \\
\hline & & & Ex. 1 & 600 & 30 & 50 & 210 & 60 & 70 & 170 \\
\hline & & & 2 & 460 & 30 & 50 & 180 & 55 & 70 & 90 \\
\hline & & & 3 & 380 & 27 & 48 & 115 & 55 & 60 & 30 \\
\hline 16 & R. C. & 27 & Control & 750 & 40 & 60 & 280 & 85 & 100 & 250 \\
\hline & & & Ex. 1 & 420 & 35 & 45 & 160 & 50 & 70 & 70 \\
\hline & & & 2 & 320 & 35 & 47 & 135 & 55 & 60 & 30 \\
\hline & & & 3 & 300 & 35 & 48 & 115 & 60 & 60 & 10 \\
\hline 17 & D. M. & 17 & Control & 940 & 42 & 55 & 272 & 85 & 135 & 370 \\
\hline & & & Ex. 1 & 390 & 30 & 47 & 172 & 55 & 55 & 30 \\
\hline & & & 2 & 330 & 32 & 46 & 130 & 55 & 55 & 25 \\
\hline & & & 3 & 300 & 28 & 46 & 105 & 52 & 50 & 25 \\
\hline 18 & H. F. & 27 & Control & 910 & 50 & 62 & 280 & 69 & 125 & 340 \\
\hline & & & Ex. 1 & 530 & 35 & 53 & 184 & 60 & 60 & 80 \\
\hline & & & 2 & 370 & 25 & 50 & 140 & 50 & 50 & 55 \\
\hline & & & 3 & 340 & 25 & 45 & 140 & 50 & 50 & 10 \\
\hline
\end{tabular}


Continued Table I.

\begin{tabular}{|c|c|c|c|c|c|c|c|c|c|c|}
\hline \multirow{2}{*}{$\begin{array}{l}\text { Case } \\
\text { No. }\end{array}$} & \multirow{2}{*}{ Name } & \multirow{2}{*}{ Age } & \multirow{2}{*}{ Condition } & \multicolumn{7}{|c|}{ Period } \\
\hline & & & & R-R & I & II & III & IV & V & VI \\
\hline \multirow[t]{4}{*}{19} & \multirow[t]{4}{*}{ T.S. } & \multirow[t]{4}{*}{37} & Control & 800 & 43 & 60 & 275 & 70 & 100 & 270 \\
\hline & & & Ex. 1 & 430 & 30 & 50 & 163 & 55 & 60 & 75 \\
\hline & & & 2 & 350 & 30 & 45 & 130 & 55 & 57 & 50 \\
\hline & & & 3 & 330 & 30 & 47 & 130 & 50 & 60 & 30 \\
\hline \multirow[t]{4}{*}{20} & \multirow[t]{4}{*}{ C. P. } & \multirow[t]{4}{*}{27} & Control & 820 & 48 & 57 & 250 & 80 & 110 & 280 \\
\hline & & & Ex. 1 & 450 & 35 & 50 & 148 & 55 & 80 & 55 \\
\hline & & & 2 & 380 & 33 & 47 & 128 & 50 & 65 & 50 \\
\hline & & & 3 & 340 & 30 & 50 & 115 & 70 & 65 & 0 \\
\hline \multirow[t]{4}{*}{22} & \multirow[t]{4}{*}{ B. H. } & \multirow[t]{4}{*}{32} & Control & 860 & 42 & 55 & 245 & 90 & 130 & 295 \\
\hline & & & Ex. 1 & 420 & 32 & 45 & 145 & 70 & 80 & 50 \\
\hline & & & 2 & 350 & 35 & 45 & 115 & 55 & 70 & 20 \\
\hline & & & 3 & 340 & - & - & 105 & 55 & 65 & 0 \\
\hline \multirow[t]{4}{*}{23} & \multirow[t]{4}{*}{ W. B. } & \multirow[t]{4}{*}{23} & Control & 940 & 41 & 60 & 300 & 65 & 115 & 418 \\
\hline & & & Ex. 1 & 390 & 32 & 50 & 168 & 50 & 60 & 65 \\
\hline & & & 2 & 350 & 25 & 50 & 130 & 47 & 50 & 45 \\
\hline & & & 3 & 330 & 25 & 50 & 110 & 45 & 50 & 30 \\
\hline \multirow[t]{4}{*}{24} & \multirow[t]{4}{*}{ D. $W$. } & \multirow[t]{4}{*}{31} & Control & 900 & 42 & 55 & 270 & 70 & 110 & 320 \\
\hline & & & Ex. 1 & 600 & 32 & 50 & 200 & 60 & 90 & 163 \\
\hline & & & 2 & 420 & 28 & 48 & 145 & 55 & 75 & 60 \\
\hline & & & 3 & 360 & 30 & 45 & 136 & 53 & 60 & 40 \\
\hline
\end{tabular}

Table II. Mean Value of Each Period in msec.

\begin{tabular}{|c|c|c|c|c|c|c|c|}
\hline \multirow{2}{*}{ Cycle length } & \multicolumn{6}{|c|}{ Period } & \multirow{2}{*}{ Total } \\
\hline & $I$ & II & III & IV & V & VI & \\
\hline 300 & 31 & 47 & 105 & 55 & 57 & 0 & 295 \\
\hline 400 & 31 & 48 & 155 & 57 & 62 & 50 & 404 \\
\hline 500 & 33 & 50 & 185 & 60 & 71 & 105 & 504 \\
\hline 600 & 35 & 52 & 210 & 64 & 81 & 160 & 602 \\
\hline 700 & 38 & 54 & 240 & 68 & 92 & 215 & 707 \\
\hline 800 & 41 & 57 & 255 & 71 & 102 & 275 & 801 \\
\hline 900 & 42 & 59 & 270 & 75 & 113 & 335 & 894 \\
\hline 1000 & 43 & 61 & 285 & 79 & 123 & 400 & 991 \\
\hline 1100 & 43 & 64 & 295 & 83 & 134 & 475 & 1094 \\
\hline 1200 & 43 & 66 & 300 & 86 & 144 & 550 & 1189 \\
\hline
\end{tabular}

The resting isometric contraction values ranged from 55 to $69 \mathrm{msec}$. with an average of $60 \mathrm{msec}$. At peak exercise the isometric contraction range was from 45 to $52 \mathrm{msec}$. with an average of $47 \mathrm{msec}$. The isometric contraction period 


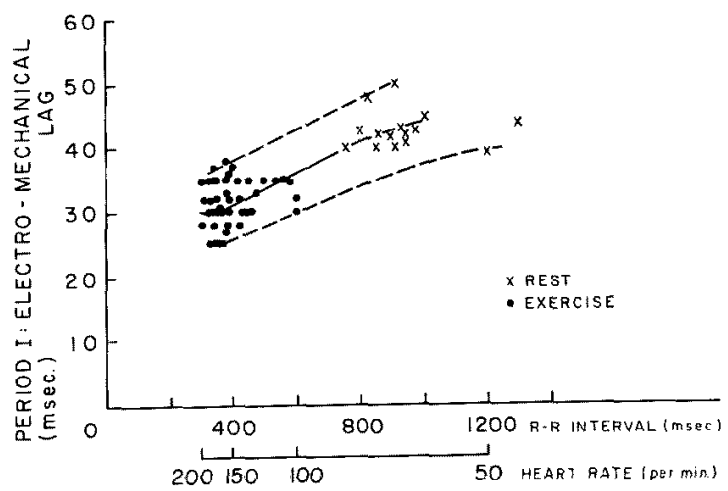

Fig. 3. Duration of the electromechanical lag period (Period I) as a function of cardiac cycle length ( $R-R$ interval).

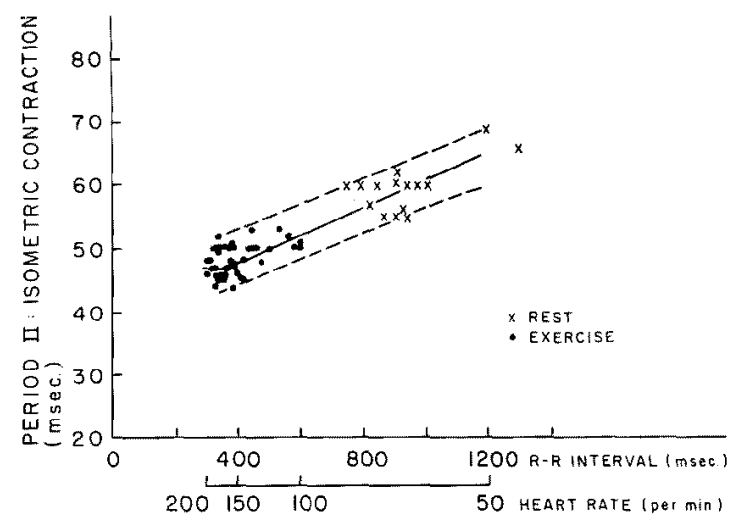

Fig. 4. Duration of the isometric contraction period (Period II) as a function of cardiac cycle length ( $R-R$ interval).

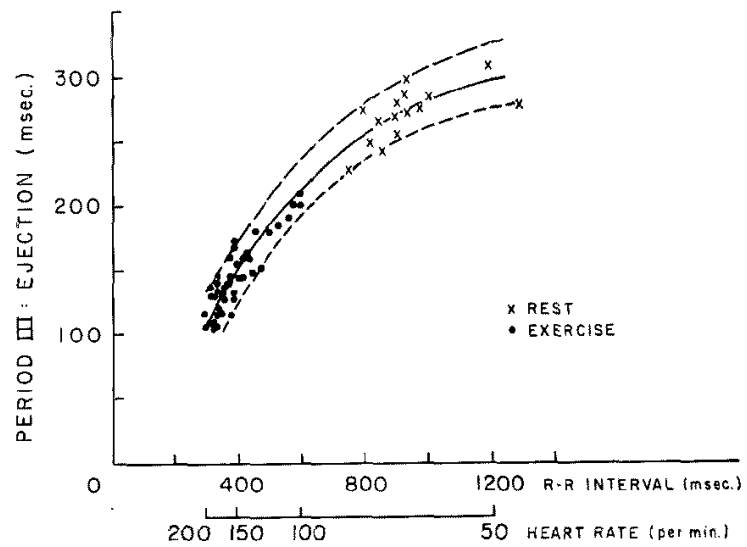

Fig. 5. Duration of the ejection period (Period III) as a function of cardiac cycle length ( $R-R$ interval). 
reached a maximum shortening at a cycle length of 370 msec. ( 160 heart rate).

Fig. 5 presents the ejection period $\left(J_{2}-L\right)$ as a function of cycle length. Under resting conditions the ejection period ranged from 240 to $300 \mathrm{msec}$. with an average of 260 msec., and at peak exercise ranged from 110 to 170 msec., with an average of $140 \mathrm{msec}$. There was a progressive shortening of the ejection period with diminished cycle length which became more pronounced at intervals of less than $370 \mathrm{msec}$. (160 heart rate).

Illustrated in Fig. 6 is the isometric relaxation period (L-M) as a function of cycle length. The range at rest is from 62 to $85 \mathrm{msec}$, and at peak exercise from 50 to $70 \mathrm{msec}$. The mean values were 78 and $52 \mathrm{msec}$, respectively. There is a progressive shortening to the ejection period with diminished cycle length which became more pronounced at intervals of less than 370 msec. (160 heart rate).

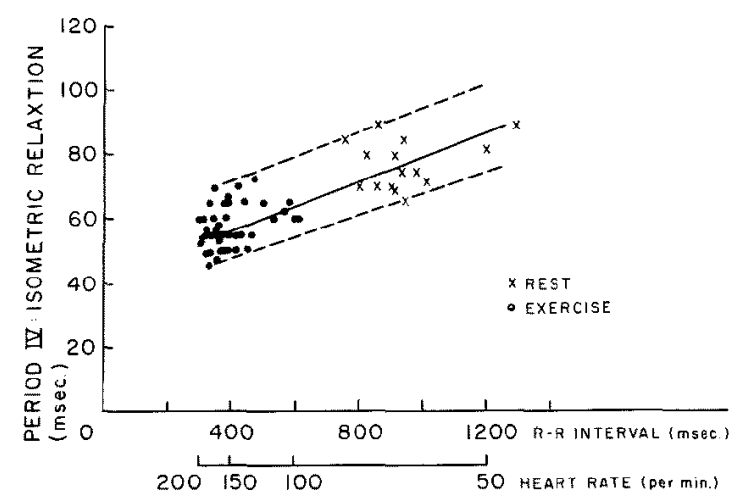

Fig. 6. Duration of the isometric relaxation period (Period IV) as a function of cardiac cycle length ( $R-R$ interval).

Illustrated in Fig. 6 is the isometric relaxation period (L-M) as a function of cycle length. The range at rest is from 62 to $85 \mathrm{msec}$. and at peak exercise from 50 to $70 \mathrm{msec}$. The mean values were 78 and $52 \mathrm{msec}$, respectively. There is a progressive shortening of the isometric relaxation period with diminished cycle length with a plateau at $370 \mathrm{msec}$. (160 heart rate).

The rapid filling phase (N-R) is shown as a function of cycle length in Fig. 7. A decrease of this interval is noted with shortened cycle length. The resting values for this period ranged from 100 to $140 \mathrm{msec}$, with a mean value of $120 \mathrm{msec}$. At peak exercise the range was 50 to $80 \mathrm{msec}$. with an average value of $60 \mathrm{msec}$. The maximum shortening was reached at a cycle length of 370 msec. (160 heart rate).

In Fig. 8 the period of diastasis is presented as a function of cycle length. 


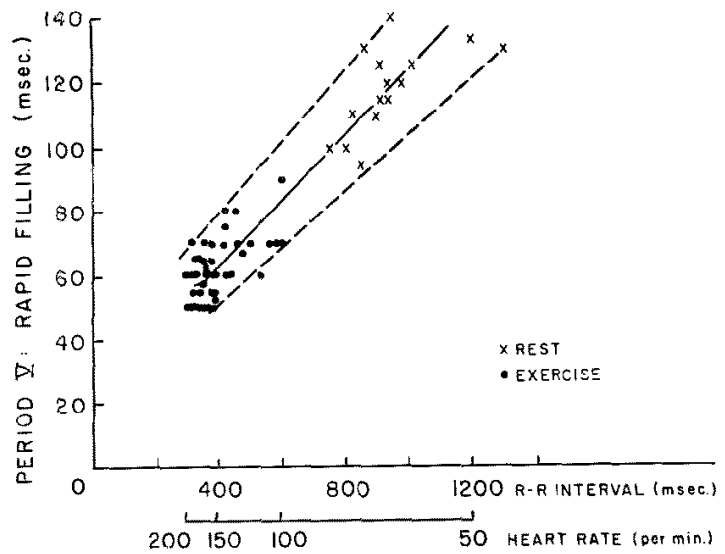

Fig. 7. Duration of the rapid filling period (Period V) as a function of cardiac cycle length (R-R interval).

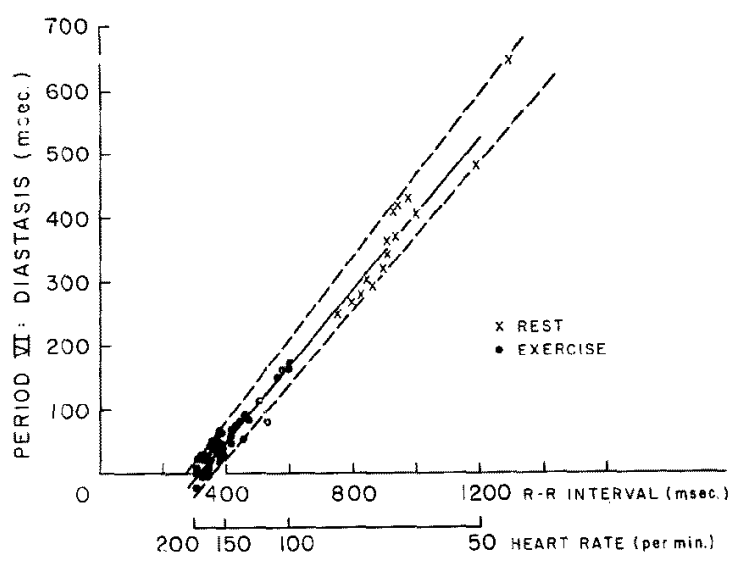

Fig. 8. Duration of the diastasis period (Period VI) as a function of cardiac cycle length ( $\mathrm{R}-\mathrm{R}$ interval).

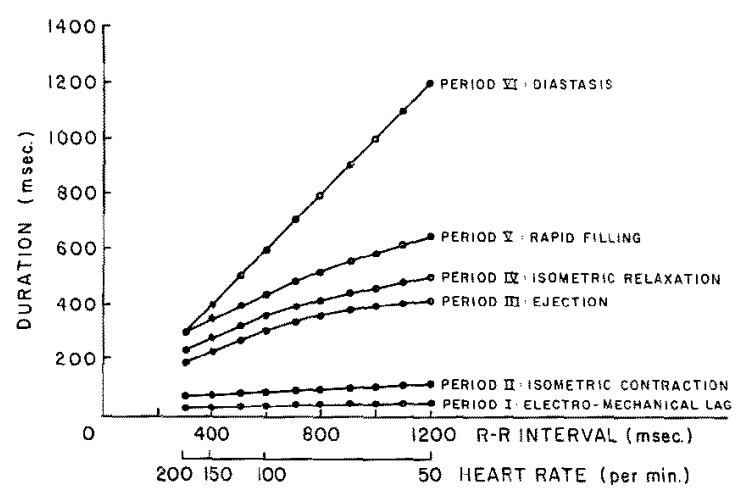

Fig. 9. Mean durations of the phases of the left heart cycle as a function of cardiac cycle length. 
There is a linear shortening of this period with diminished cydle length. At rest, diastasis ranged from 280 to $420 \mathrm{msec}$. with an average of $320 \mathrm{msec}$. At peak exercise it ranged from 0 to $100 \mathrm{msec}$. with an average of $30 \mathrm{msec}$.

The mean values of the 6 periods are summarized in Fig. 9 which shows the overall relationships of these intervals to cycle length and to heart rate.

\section{Discussion}

There has been greater attention given to the study of the phases of the heart cycle in humans because of the ability of external techniques to determine these periods reliably. However, data are limited primarily to studies on total systole and diastole. Few attempts have been made to measure the subdivisions of these major phases.

The data obtained in these studies compare favorably with those obtained by others using direct and indirect methods. Braunwald, ${ }^{101}$ who studied the electromechanical lag period using intraventricular pressure curves, found this period to average $52 \mathrm{msec}$. but made no conclusions regarding the relationship of this period to heart rate. Harrison, ${ }^{5)}$ who studied this period using the kinetocardiogram, found it to average $38 \mathrm{msec}$. He stated that limitations in his measurement accuracy did not permit any conclusions on alterations of this interval with heart rate. Coghlan ${ }^{11)}$ et al. also found the same values using intraventricular pressure curves. De Palma ${ }^{12)}$ who studied this interval in cats, found that it was shortened with increased heart rates.

The data obtained in our resting subjects compare favorably with those of Harrison. The heart rate range in this study was of a much greater magnitude than either that of Harrison or Braunwald, thus explaining our findings of changes in the electromechanical lag period with heart rate.

Braunwald ${ }^{10)}$ studied the isometric contraction interval in humans and found it to average $61 \mathrm{msec}$. Harrison ${ }^{5)}$ obtained a $68 \mathrm{msec}$. average and concluded that the interval was not affected by heart rate in the resting subject. The resting values obtained in our studies compare well with those of Braunwald and Harrison. However, it was our finding that the isometric contraction interval shortened with increases in heart rate an average of $13 \mathrm{msec}$.

All of the available studies on ejection time show that this interval is a function of heart rate. ${ }^{13)}$ Although the absolute value of ejection time may vary according to the technique used, the changes with heart rate in normal subjects have been shown to be the same. Our data show a progressive decrease of ejection time with increases in heart rate up to maximal heart rate levels.

The isometric relaxation period has been studied by Benchimol et al. ${ }^{3}$ 
using the apex cardiogram and was found to range from 40 to $80 \mathrm{msec}$. No conclusions were made regarding changes in this interval with heart rate. Harrison $^{5)}$ has also studied this interval and found that there was an inverse relationship between heart rate and the isometric relaxation period. Our data show a similar range of this period and also indicate a progressive shortening with increased heart rate.

The only available data on the period of rapid filling have been obtained by Benchimol et al. ${ }^{3}$ They found that this period ranged from 40 to 120 msec. and was directly related to the total diastolic period. Our data indicate that the range of this period is similar and confirm the findings that it is directly a function of the total diastolic period (Fig. 10).

There were no studies found concerning the period of diastasis in the normal human subject.

The close agreement between the durations of cardiac events obtained in this study and those obtained by other methods lends further support to the use of vibrocardiograms for timing the events of the heart cycle.

The variations of the 6 periods of the left heart cycle which were summarized in Fig. 9 illustrate the finding that the period of diastasis is affected to a greater extent than the other cardiac phases by changes in heart rate. The electromechanical lag, isometric contraction, isometric relaxation and rapid filling phases change minimally throughout the heart rate range. It is interesting to note that above a heart rate of 160 the period of diastasis is completely eliminated. At this heart rate level, the other phases also undergo variations. The electromechanical lag period tends to plateau or increase slightly, isometric contraction tends to plateau or increase slightly, ejection tends to shorten markedly, and isometric relaxation and rapid filling plateau or increase slightly. These findings suggest that a physiologic limit in heart rate is being achieved.

\section{Summary and Conclusions}

The phases of the left heart cycle have been measured in athletes at rest and during exercise utilizing vibrocardiographic and electrocardiographic data. Six periods were studied which corresponded to electromechanical lag, isometric contraction, ejection, isometric relaxation, rapid filling, and diastasis. These periods were compared with the total length of the left heart cycle at heart rates ranging from 50 to 200 beats per min. The rangc of these intervals was such that the duration of any cardiac phase could be predicted from ventricular cycle length.

The 6 periods of the left heart cycle all diminished linearly with cycle length up to heart rates of 160 . After this level, the electromechanical lag and 
isometric contraction periods remained unchanged, the ejection period shortened more markedly, and the isometric relaxation and rapid filling periods did not change. The period of diastasis demonstrated a marked shortening and was found to be completely eliminated above heart rates of 160 . It was suggested that a physiologic limit of heart rate is achieved near this level.

\section{References}

1. Wiggers, C. J., Pressure Pulses in the Cardiovascular Systems, University Press, Aberdeen, Scotland, 1927.

2. Dimond, E. G. and Benchimol, A. : Brit. Heart J. 25 : 389, 1963.

3. Benchimol, A., Dimond, E. G., and Carson, J. C.: Am. Heart J× 61 : 485, 1961.

4. Legler, J. I., Benchimol, A., and Dimond, E. G.: Brit. Heart J. 25: 246, 1963.

5. Harrison, T. R., Dixon, K., Russell, R. O., Jr., Bidwai, P. S., and Coleman, H. N.: Am. Heart J. 67 : 189, 1964.

6. Agress, C. M., Wegner, S., Bleifer, D. J., Estrin, H. M., Schroyer, K., and Labins, G. : Am. J. Cardiol. 13 : 340, 1964.

7. Agress, C. M., Wegner, S., and Nakakura, S. : Jap. Heart J. 5 : 414, 1964.

8. Agress, C. M., Wegner, S., Bleifer, D. J., Lindsey, A., Van Houten, J., Schroyer, K., and Estrin, H. M. : Am. J. Cardiol. 13 : 226, 1964.

9. Agress, C. M. and Nakakura, S. : Aero. Med. 35 : 752, 1964.

10. Braunwald, E., Fishman, A. P., and Cournand, A.: Circulat. Res. 4: 100, 1956.

11. Coghlan, C., Prieto, G., and Harrison, T. R.: Am. Heart J. 62 : 65, 1961.

12. DePalma, J. R.: Am. J. Physiol. 180: 96, 1055.

13. Jones, W. B. and Foster, G. L. : J. Appl. Physiol. 19 : 279, 1964. 